\title{
Precrack Hysteresis Energy in Determining Polycarbonate Ductile-Brittle Transition. IV. Effect of Strain Rate
}

\author{
KUO-CHAN CHIOU, HON-CHUN HSU, FENG-CHIH CHANG \\ Institute of Applied Chemistry, National Chiao-Tung University, Hsinchu, Taiwan, Republic of China
}

Received 7 August 1996; accepted 24 November 1996

\begin{abstract}
Effect of deformation rate on the ductile-brittle transition behavior for polycarbonate (PC) with different molar mass, notch radius, and rubber content has been investigated. PC with higher molar mass, notch radius, or rubber-modification possesses a higher critical strain rate when the ductile-brittle transition occurs. Whether a notched specimen will fail in a ductile mode or a brittle mode is already decided before the onset of the crack initiation. If size of the precrack plastic zone exceeds a critical level prior to onset of crack initiation, the crack extension developed later will propagate within the plastic zone and result in a ductile mode fracture. The precrack elastic storage energy, the input energy subtracting the hysteresis energy, is the main driving force to strain the crack tip for crack initiation. The precrack hysteresis energy (directly related to the precrack plasticity) increases with the decrease of the applied strain rate. Therefore, the strain rate is also closely related to the size of the precrack plastic zone. If the strain rate is lower than the critical strain rate, the specimen is able to grow a precrack plastic zone exceeding the critical plastic zone and results in a ductile mode fracture. (C) 1997 John Wiley \& Sons, Inc. J Appl Polym Sci 65: 655-665, 1997
\end{abstract}

Key words: polycarbonate; ductile-brittle transition; hysteresis; strain rate

\section{INTRODUCTION}

The complicated brittle-ductile transition (BDT) or ductile-brittle transition (DBT) behavior has received considerable attention for practical safety reasons. $\mathrm{Wu}^{1,2}$ proposed that the brittle/ductile (craze/ yield) behavior of a polymer is controlled by two chain parameters, entanglement density $\left(\nu_{e}\right)$ and characteristic ratio of the chain $\left(C_{\infty}\right)$. Lyu, Zhu, and $\mathrm{Qi}^{3}$ proposed a new criterion of BDT by combining fracture stress $\left(\sigma_{b}\right)$ and shear yielding stress $\left(\sigma_{y}\right)$ into a dimensionless group $D_{a}=\sigma_{b}^{2} / \sigma_{y}^{2}$. Ward ${ }^{4}$ reviewed the BDT behavior and characterized it by a critical length $\chi_{o c}=\alpha G_{c} E / \sigma_{y}^{2}$, where $\alpha$ is a number constant whose value is determined by the stress field in the test. The critical length is the plastic zone

Correspondence to: F.-C. Chang.

Contract grant sponsor: National Science Council, Republic of China.

(c) 1997 John Wiley \& Sons, Inc. CCC 0021-8995/97/040655-11 at a general yield of a notched bar and the transition occurs at the temperature (DBTT) at which the quantity of $\alpha G_{c} E / \sigma_{d y}^{2}$ is equal to the critical length in the chosen test.

Fracture behavior of $\mathrm{PC}$ has attracted particular interest because it shows a distinctive DBT in response to numerous extrinsic and intrinsic variables. An extensive review on the DBT behavior of polycarbonate has been made in our earlier report. ${ }^{5}$ For the notched PC specimens within the transition range, either ductile or brittle fracture mode is possible with identical geometry and test conditions, and rarely result in mixed modes with fracture energy at the average of both modes. For example, by varying the test temperatures, the DBTT of the standard notched impact strength of $\mathrm{PC}$ is not a single temperature, but, rather, a temperature range.

Since the stress field surrounding the crack tip region under deformation is inhomogeneous, a simple stress competitive criterion to dictate whether a fracture is ductile or brittle mode may be oversimplified. Whether a fracture is ductile or brittle, the 
whole fracture process has to be taken into consideration. We have discovered a close relationship between the precrack hysteresis energy and the corresponding DBT behavior for PC that is applicable to the molar mass, ${ }^{6}$ rubber content, ${ }^{7}$ and temperature. ${ }^{8}$ The total input energy at the onset of the crack initiation can be divided into elastic storage and inelastic plastic energy. Part of the precrack inelastic energy eventually converts into heat and a plastic zone ahead of the crack tip. For the brittle materials, fracture mechanics are applicable because the plastic zone is small and limited around the crack tip. On the contrary, for the ductile materials, the precrack hysteresis energy and the corresponding plasticity are too significant to be neglected. If the size of the precrack plastic zone exceeds a critical value prior to the onset of the crack initiation, the crack propagation will occur later through the plastic zone and results in ductile fracture as long as the crack front propagates within the plastic zone. If the precrack plastic zone is too small at the onset of the crack initiation to contain the propagating crack front, a brittle failure occurs.

Therefore, we proposed the existence of a critical precrack plastic zone $\left(V_{c}\right)$ in determining whether the failure is a ductile or a brittle mode. ${ }^{6-8}$ When the precrack plastic zone $V_{p}>V_{c}$ before onset of initiation, a ductile tearing mode occurs. If $V_{p}<V_{c}$ at onset of crack initiation, a brittle-mode crack occurs. If $V_{p}=V_{c}$ at onset of initiation, a brittle, a ductile, or even a semiductile mixed-mode fracture may occur. However, semiductile fracture rarely occurs in the notched PC specimen. The semiductile mode is considered as a fracture of mixed mode of ductile and brittle that can either proceed simultaneously or sequentially during the whole fracture process. ${ }^{6-8}$ A semiductile fracture can be in the form of the ductile mode in the front portion of the specimen and shifts into brittle mode in the rear part of the specimen, or vice versa. ${ }^{6-8}$

The purpose of this article is to discuss the applicability of the same concept of hysteresis theory to explain the behavior of the DBT behavior of PC and elastomer-modified PC in terms of different deformation rate, notch radius, and molar mass.

\section{EXPERIMENTAL}

Natural-grade PC samples with various melt flow rates (MFR) were obtained from the Dow Chemical Co. Molar mass was determined by GPC using methylene chloride as a solvent, and the results
Table I Polycarbonate Densities, MFR, and MW

\begin{tabular}{cccc}
\hline PC MFR & $M_{w}\left(\times 10^{3}\right)$ & $M_{n}\left(\times 10^{3}\right)$ & Density $(\mathrm{g} / \mathrm{mL})$ \\
\hline 3 & 35.9 & 13.3 & 1.19740 \\
6 & 31.5 & 11.6 & 1.19820 \\
10 & 28.2 & 10.6 & 1.19850 \\
15 & 25.1 & 9.7 & 1.19860 \\
20 & 23.9 & 9.5 & 1.19860 \\
60 & 19.6 & 8.3 & 1.19870 \\
\hline
\end{tabular}

are shown in Table I. Density of the PC pellets was determined by a density-gradient column, model DC-1, from Techne Cambridge Limited, and the results are also listed in Table I. Coreshell elastomer, EXL-3330, was obtained from Rohm \& Hass. Experimental procedures including extrusion blending, injection molding, Izod impact, slow-rate fracture, hysteresis, and scanning electron microscopy (SEM) were reported previously. ${ }^{6-8}$

\section{RESULTS AND DISCUSSION}

\section{Theoretical Background on the Effect of Strain Rate}

The yield behavior of glassy polymers is very much dependent upon the temperature and the rate of testing. Bauwens-Crowet, Bauwens, and Homes ${ }^{9}$ studied the dependence of yield stress of $\mathrm{PC}$ on strain rate under different temperatures and modeled this dependence using the Eyring theory of viscosity. ${ }^{10,11}$

$$
\frac{\left|\sigma_{y}\right|}{T}=\frac{\Delta E^{*}}{v^{*} T}+\left(\frac{R}{v^{*}}\right) \ln \left(\frac{\dot{e}}{A_{E}}\right)
$$

where $\Delta E^{*}$ is the activation energy, $v^{*}$ is the activation volume, $R$ is the gas constant, and $A_{E}$ is a constant. In a notched beam test, the strain rate at the notch tip is considerably higher than the rest part of the specimen and the local strain rate has been estimated to be of the order of $5 \times 10^{3}$ $\mathrm{s}^{-1}$. We can easily understand from the above equation that higher strain rate near the vicinity of crack tip region will cause a substantial increase of the yield stress, while the breaking stress ( craze stress) is normally less temperatureand strain-rate dependent. Higher yield stress 


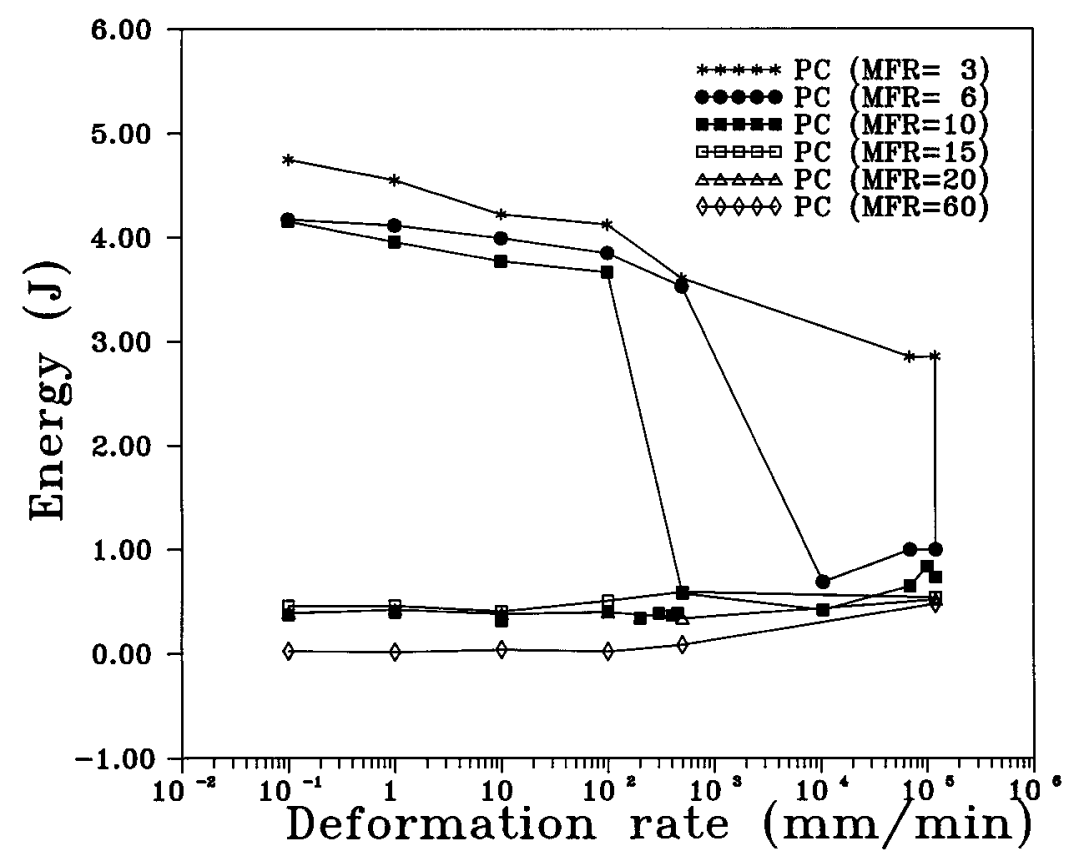

Figure 1 Fracture energy of PC ( $\frac{1}{4}$ in. ) as a function of deformation rate by varying melt flow rate.

will produce a relatively smaller precrack plastic zone ahead of the crack tip at the onset of the crack initiation, and therefore tends to form a brittle failure mode. The addition of elastomer would reduce the yield stress, and this factor alone is able to retard or delay the onset of the crack initiation and compensates for the higher yield stress caused by higher strain rate. The velocity of a hammer striking of the typical Izod impact test is $\sim 2 \mathrm{~m} / \mathrm{s}$.

\section{Effect of Molar Mass and Strain Rate}

Figure 1 illustrates the effect of strain rate ranging from 0.1 to $120,000 \mathrm{~mm} / \mathrm{min}$ on fracture energy of $\frac{1}{4}$ in. thickness specimens of PCs with various MFRs. In general, the specimens with lower MFR (higher molar mass) have slightly higher fracture energy than those with higher MFR on both ductile and brittle fractures. The PC with MFR $=3$ (PC3) has the critical rate of DBT at $120,000 \mathrm{~mm} / \mathrm{min}$ where both ductile and brittle modes occur. At this critical deformation rate of $120,000 \mathrm{~mm} / \mathrm{min}$, the fracture energy of the ductile mode is only $\sim 60 \%$ of the fully ductile fracture energy occurring at lower deformation rates. That means the PC3 fracture at such a high impact rate is only a ductile-dominant mode rather than as a fully ductile mode of fracture. PC6 shows exclusively ductile fracture up to $500 \mathrm{~mm} /$ min, and the ductile-brittle transition rate (DBTR) is located at somewhere between 500$10,440 \mathrm{~mm} / \mathrm{min}$. PC10 shows the most unusual DBT behavior among all under the specific condition of the test. PC10 has both ductile and brittle modes of fractures up to $450 \mathrm{~mm} / \mathrm{min}$ and the probability of brittle mode increases with increasing the deformation rate. At $500 \mathrm{~mm} / \mathrm{min}$ and higher, PC10 results in brittle fracture exclusively. That means the PC10 has very broad DBTR under the tested conditions. PCs with higher MFR (PC15, PC20, and PC60) result in only brittle fracture even at the slowest deformation rate of $0.1 \mathrm{~mm} / \mathrm{min}$. It is worthy to mention here that the PC60 with the lowest molar mass results in substantially lower brittle fracture energy relative to the rest PCs. The reasons for greater ductility of the higher molar mass PC come from more entanglements per chain and slightly lower yield stress that was mentioned previously. ${ }^{6}$

Selected SEM photomicrographs of the fractured surfaces for PC3 tested under different strain rates are shown in Figure 2(A-E). From the morphological results of Figure 2, the strain rate is clearly an important variable in determining the failure mode of $\mathrm{PC}$. At higher strain rates, the brittle fractured surfaces [Fig. 2(A,B)] show 


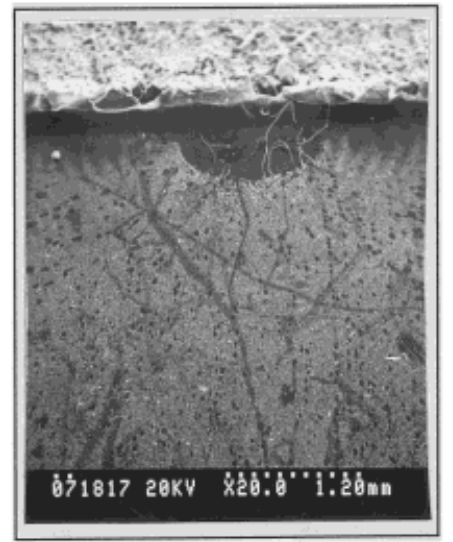

(A) strain rate $=120,000 \mathrm{~mm} / \mathrm{min}$

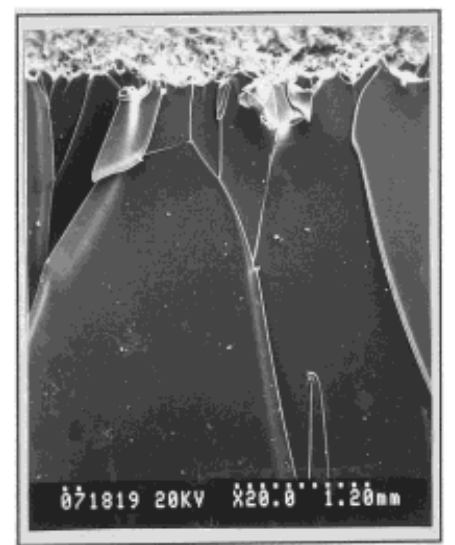

(C) strain rate $=100 \mathrm{~mm} / \mathrm{min}$

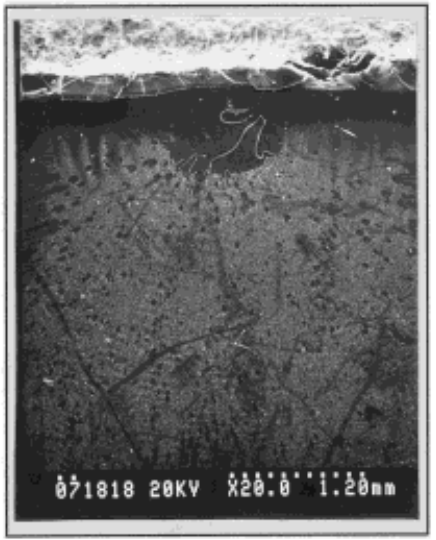

(B) strain rate $=69,000 \mathrm{~mm} / \mathrm{min}$

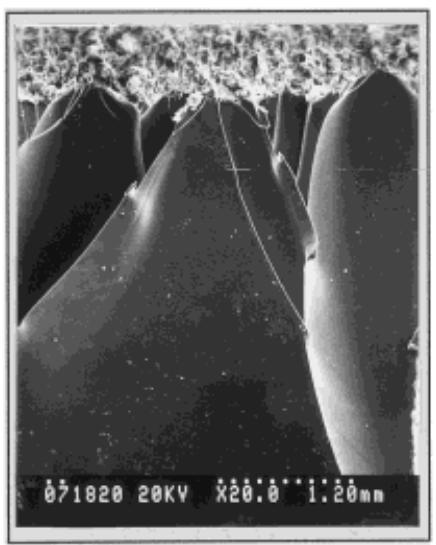

(D) strain rate $=10 \mathrm{~mm} / \mathrm{min}$

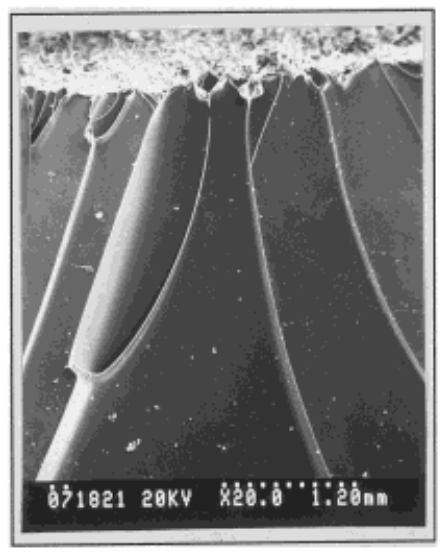

(E) strain rate $=1 \mathrm{~mm} / \mathrm{min}$

Figure 2 SEM micrographs of the fracture surfaces of PC3 ( $\frac{1}{4}$ in. $)$ tested at various strain rates. (A) strain rate $=120,000 \mathrm{~mm} / \mathrm{min}$, brittle; (B) strain rate $=69,000 \mathrm{~mm} /$ min, brittle; (C) strain rate $=100 \mathrm{~mm} / \mathrm{min}$, ductile; (D) strain rate $=10 \mathrm{~mm} / \mathrm{min}$, ductile; (E) strain rate $=1 \mathrm{~mm} / \mathrm{min}$, ductile. 


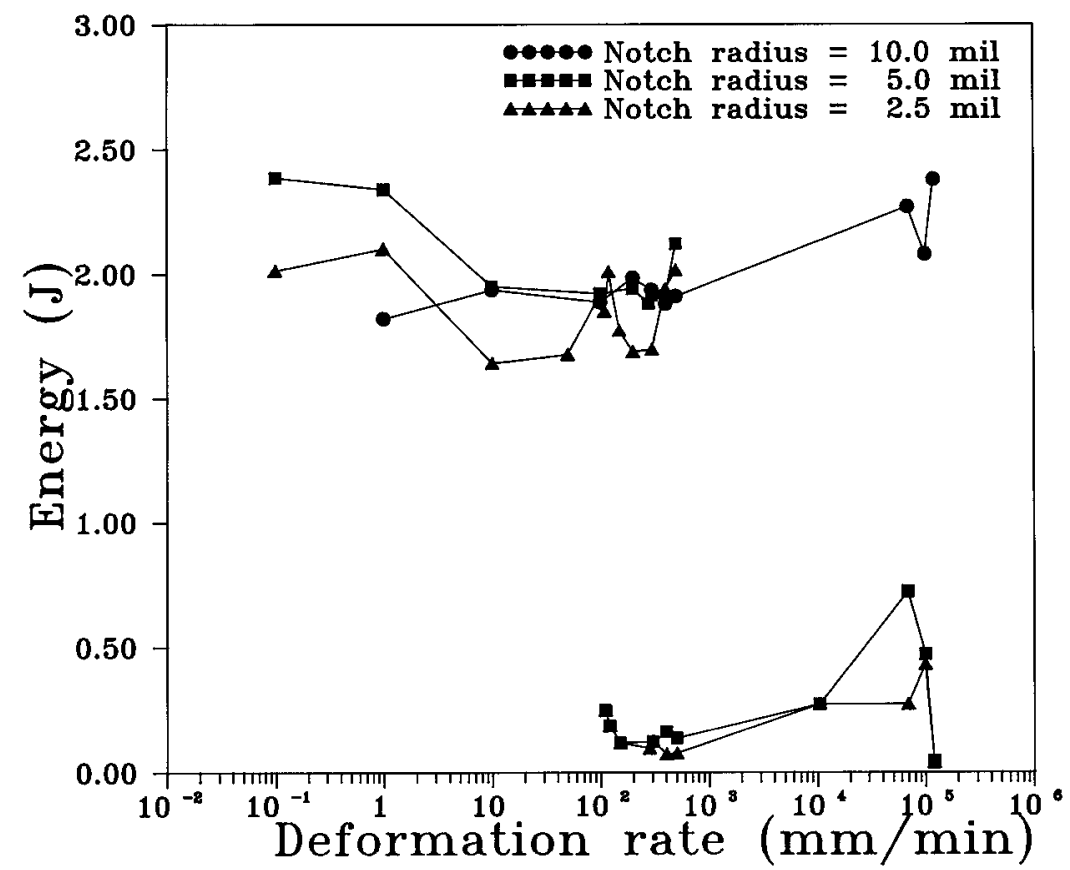

Figure 3 Fracture energy of $\mathrm{PC}$ ( $\mathrm{MFR}=15, \frac{1}{8} \mathrm{in}$.) as a function of deformation rate by varying notch radius.

no sign of lateral contraction and the surfaces are flat with a small diffuse zone near the crack tip region. Those ductile fractured surfaces [Fig. $2(\mathrm{C}-\mathrm{E})]$ tested under lower strain rates appear distorted and irregular with clear lateral contraction and extensive shear yielding.

\section{Effect of Notch Radius on DBTR}

The fracture energy of PC15 (thickness $=\frac{1}{8}$ in.) by varying notch radius and deformation rate is shown in Figure 3. The DBTR is in the range of $300-500 \mathrm{~mm} / \mathrm{min}$ for the specimens with notch radius of $2.5 \mathrm{mil}$ and in the range of $110-500$ $\mathrm{mm} / \mathrm{min}$ for the notch radius of $5 \mathrm{mil}$. For the specimens with notch radius of 10 mil, all specimens fail exclusively in ductile tearing mode within the deformation rates investigated. Therefore, a specimen with a greater notch radius has higher fracture energy and higher DBTR as would be expected. The geometry of a greater notch radius creates less stress concentration straining the crack tip and can better resist the crack initiation. Additionally, a greater notch radius has a relatively lower local strain rate and therefore has relatively lower yield stress than an identical specimen with smaller notch radius.

For the ductile and high-energy fracture, the fracture surface appears distorted and irregular.
Below the notch, the surface shows a clear lateral contraction, indicating a plane-stress ductile fracture. The striations on the fracture surface spread uniformly from the root of the notch along the direction of crack propagation. The SEM photomicrographs showing the effect of notch radius on the fracture surfaces under the strain rate of $69,000 \mathrm{~mm} / \mathrm{min}$ are given in Figure $4(\mathrm{~A}-\mathrm{C})$. The PC with standard notch radius (10 mil) shows clear lateral contraction and has striating lines on the fractured surface, as shown in Figure 4(A). PC with sharper notch radius (5 mil or 2.5 mil) possesses the characteristic brittle fracture surfaces showing brittle type striating lines but no lateral contraction [Fig. 4(B,C)]. The covering area and the numbers of striating lines of the PC with greater notch radius ( 5 mil) are more than those of the PC with sharper notch radius (2.5 mil). The mirror transition zone near the crack tip region is also higher for the specimen with greater notch radius [compare Fig. 4(B, C)]. This transition area is a fast crack jump zone immediately after the onset of crack initiation. Greater transition zone area indicates the specimen can better resist crack initiation by better blunting the crack tip. According to our previously proposed model, ${ }^{6}$ the ductile fracture is due to the propagating crack front proceeding behind the front line of the extending plastic zone. If the pre- 


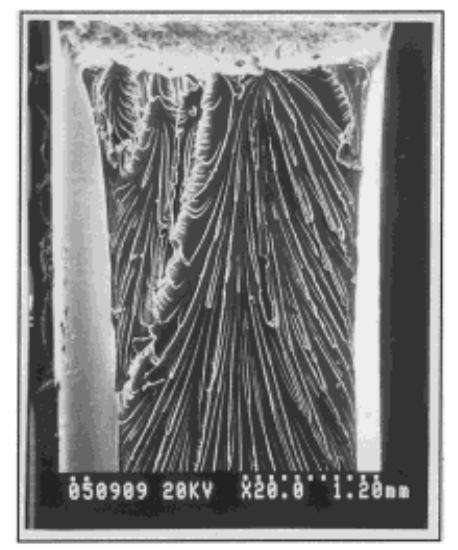

(A) Notch radius $=\mathbf{1 0}$ mil

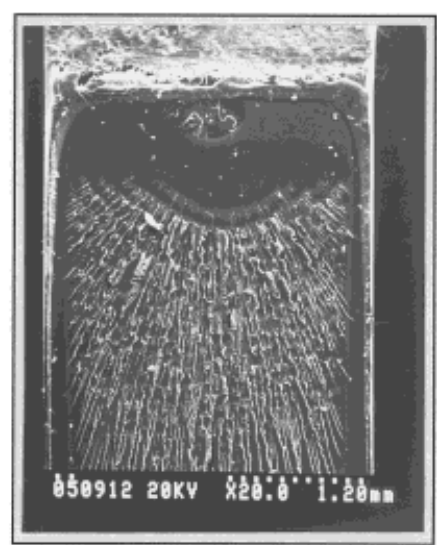

(B) Notch radius $=5$ mil

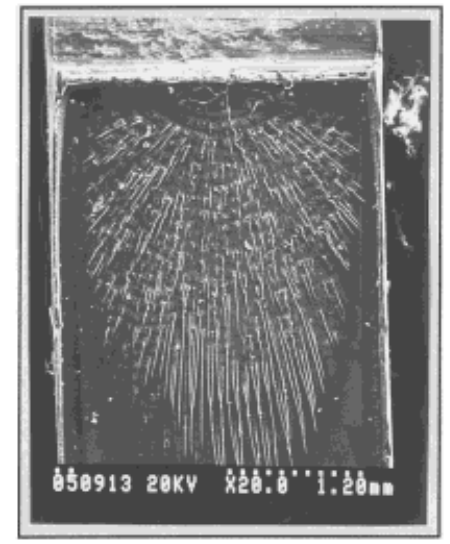

(C) Notch radius $=2.5 \mathrm{mil}$

Figure 4 SEM micrographs of the fracture surfaces of PC15 ( $\frac{1}{8}$ in. $)$ by varying notch radius tested at the strain rate $=69,000 \mathrm{~mm} / \mathrm{min}$. (A) $10 \mathrm{mil}$; (B) $5 \mathrm{mil}$; (C) $2.5 \mathrm{mil}$.

crack plastic zone is too small at onset of crack initiation to contain the propagating crack front within the plastic zone, the brittle failure occurs.

\section{Precrack Hysteresis Under Different Deformation Rates}

The hysteresis concept can only be applied strictly when the deformed material returns to its original shape. However, in our loose definition, hysteresis is the area difference between the loading and unloading curves. Figure 5 shows typical examples of the cyclic load-unloaded curves by using displacement-controlled condition and varying maximum loads for the $\frac{1}{8}$-in. modified polycarbonate (PC15 + 10\% elastomer $)$. A lower deforma- tion rate results in higher displacement, hysteresis energy, total input energy, and permanent displacement (at a fixed load maximum). The precrack hysteresis loop can be attributed to plasticity, viscoelasticity, crazes, and microcracks. These various types of energy dissipations do not occur separately, but interrelate with each other to some extent. Distinguishing or quantifying these complicated and overlapping fracture processes is very difficult, if not impossible. However, the trend of higher precrack plasticity resulting from greater hysteresis energy dissipation is undeniable. At the rate of $100 \mathrm{~mm} / \mathrm{min}$ (curve A, Fig. 5), the unloading line is actually above the loading line near the peak maximum region of the hysteresis loop. The exact nature of this observed 


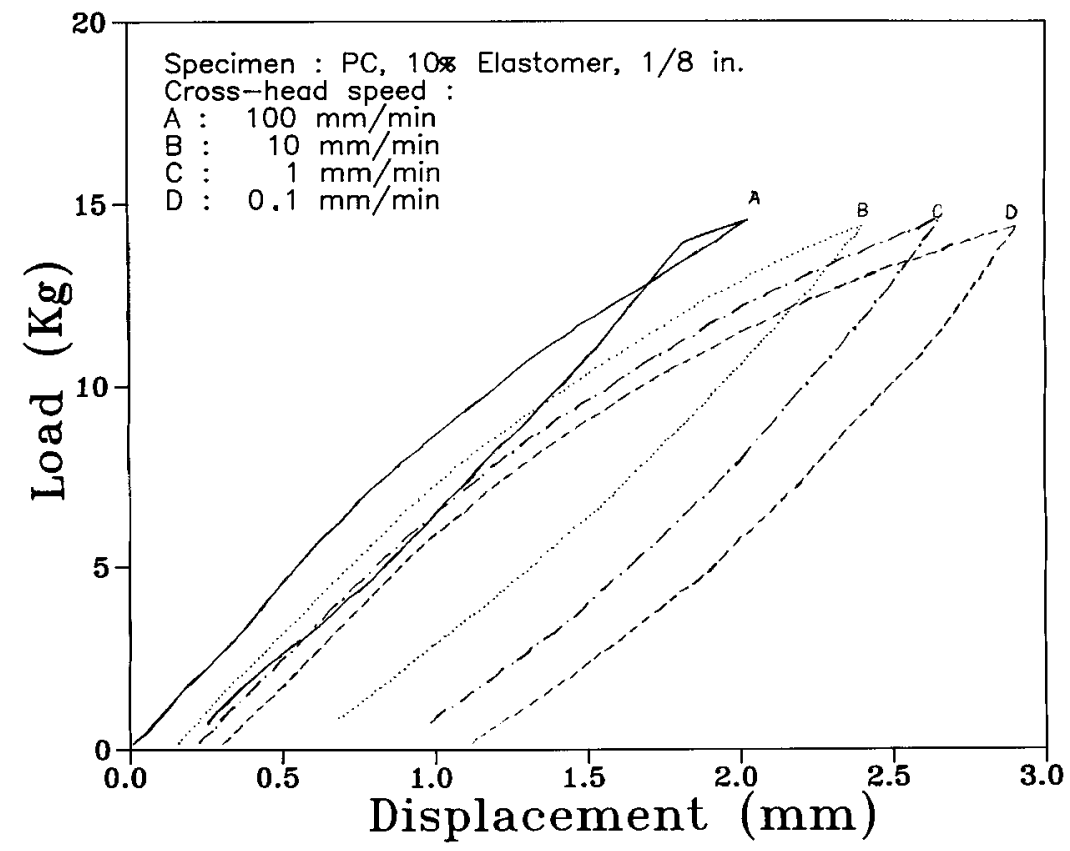

Figure 5 Load and unloading curves of elastomer-modified PC15 at various strain rates.

phenomenon is not very clear; it could be the result of the viscoelastic nature of a polymeric material or simply an instrumental problem. The extent of such load bounce is increased with the increase of deformation rate and the decrease of the maximum load level. ${ }^{6}$

The effect of notch radius on hysteresis energy under different load levels is shown in Figure 6. We will concentrate on the results from the PC15 samples of $\frac{1}{8}$-in. thickness deforming at the strain rate of $10 \mathrm{~mm} / \mathrm{min}$ and three different controlled maximum loads (load $=0.2,0.15,0.1 \mathrm{kN}$ ). Results show that the precrack hysteresis energy increases with the increase of the load and the notch radius.

Effects of strain rate on precrack hysteresis energy of unmodified and elastomer-modified PC are summarized in Table II and Figures 7-9. We have demonstrated that the main strain energy for crack initiation is the storage energy; the input energy subtracts the hysteresis energy. Greater hysteresis energy implies less storage energy ( storage $E=$ input $E$ - hysteresis $E$ ) available to strain the crack tip for crack initiation. For those higher hysteresis specimens, additional input energy is required in order to reach the critical storage energy required for crack initiation. That is why a specimen possessing higher precrack hysteresis can resist crack initiation better. Figure 7 shows effect of deformation rate on the resultant hysteresis energy for the unmodified and the elastomer-modified PC15. Lower deformation rate results in higher hysteresis energy and the modified PC also possesses substantially higher hysteresis energy than the corresponding unmodified one. Figure 8 displays the relation between hysteresis energy and the corresponding displacement by varying deformation rate for the unmodified and elastomer-modified PC15. A lower deformation rate results in greater displacement and higher hysteresis energy. Figure 9 shows plots of permanent displacement versus hysteresis energy under different deformation rates. Rubber modification and slower deformation rate result in greater permanent displacement. If the hysteresis comes strictly from viscoelasticity, the permanent displacement should be zero. Therefore, greater permanent displacement implies greater precrack plasticity and thus greater precrack plastic zone. A close relation between the precrack hysteresis energy and the size of the precrack plastic zone has been demonstrated previously. ${ }^{6}$

\section{Elastomer-Toughening Mechanism}

The stress distribution in a notched specimen is highly complex during a fracture process. The presence of a notch produces stress concentration and creates a triaxial stress state for a thicker specimen below the notch. The Tresca yield crite- 


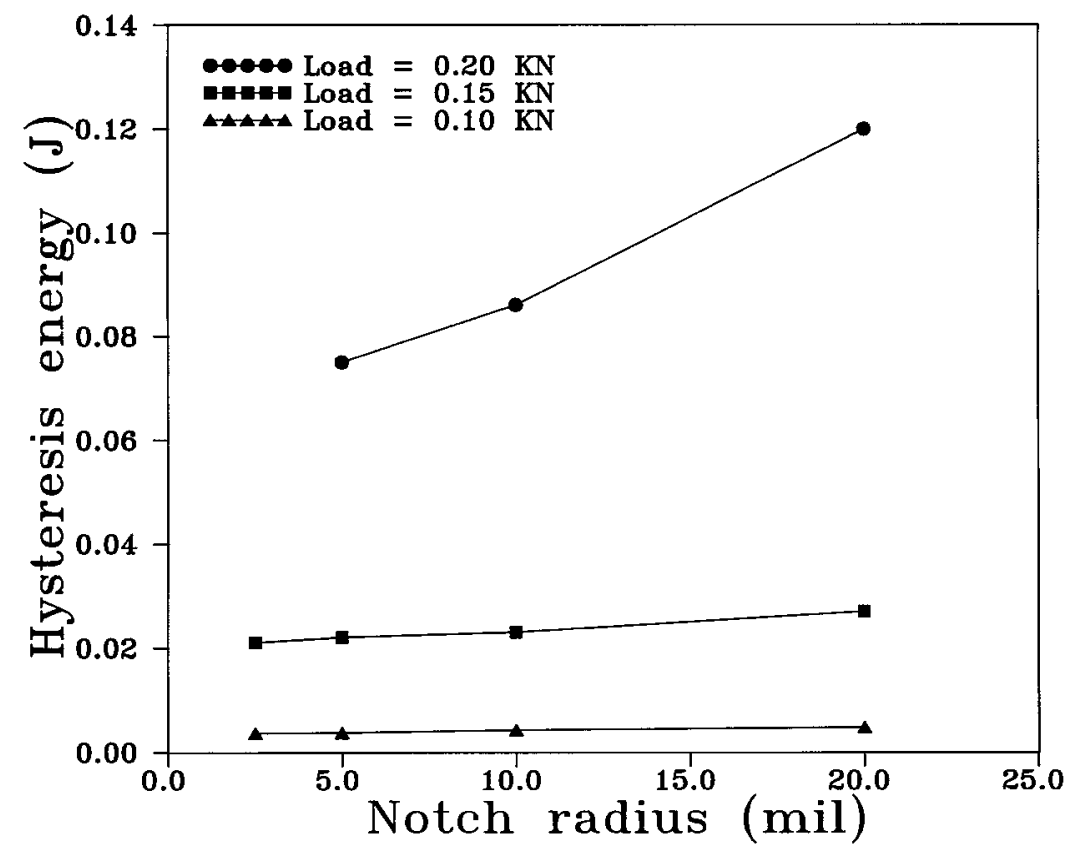

Figure 6 Plots of hysteresis versus notch radius for PC15 ( $\frac{1}{8}$ in. ) under three controlled loads.

rion predicts that the stress in plane-stress conditions is the uniaxial yield stress, $\sigma_{y}$. However, under the plane-strain conditions the yield stress is given by $\left(\sigma_{y}+\sigma_{2}\right)$, where the $\sigma_{2}$ is the smallest principal stress. The presence of elastomer particles (above its $T_{g}$ ) is able to cavitate to relieve triaxial stress caused by the plane-strain condition that is believed the main toughening mechanism to enhance shear yielding formation. Macro- scopically, we will divide the elastomer-toughening pseudoductile matrices phenomenologically into two major parts ${ }^{7}$ : promotion of brittle-to-ductile failure through mass shear yielding and elastomer-induced localized shear yielding. In any fracture, these two mechanisms can exist separately or occur and overlap simultaneously. The former is dominant in the ductile fracture and the latter is dominant in the brittle failure. Fracture

Table II Effect of Strain Rate on Hysteresis of PC $(M F R=15)$ and PC $($ MFR $=15)+10 \%$ EXL-3330 $\left(0.15 \mathrm{kN}, 10 \mathrm{~mm} / \mathrm{min}, \frac{1}{8}\right.$ in. $)$

\begin{tabular}{lcccc}
\hline & \multicolumn{3}{c}{ Rate $(\mathrm{mm} / \mathrm{min})$} \\
\cline { 2 - 4 } \multicolumn{1}{c}{ Sample } & 0.10 & 1 & 10 & 100 \\
\hline PC15 & & & \\
Displacement (mm) & 1.720 & 1.590 & 1.350 & 1.230 \\
Permanent Displacement (mm) & 0.389 & 0.267 & 0.155 & 0.039 \\
Total Energy (J) & 0.143 & 0.128 & 0.115 & 0.089 \\
Percent Hysteresis & 35.90 & 27.00 & 19.80 & 4.500 \\
Hysteresis Energy (J) & 0.051 & 0.034 & 0.023 & 0.004 \\
PC 1510 & & & \\
Displacement (mm) & 2.700 & 2.520 & 2.310 & 2.100 \\
Permanent Displacement (mm) & 0.844 & 0.758 & 0.536 & 0.165 \\
Total Energy (J) & 0.243 & 0.221 & 0.202 & 0.189 \\
Percent Hysteresis & 50.10 & 45.80 & 35.80 & 15.40 \\
Hysteresis Energy (J) & 0.122 & 0.101 & 0.073 & 0.029 \\
\hline
\end{tabular}




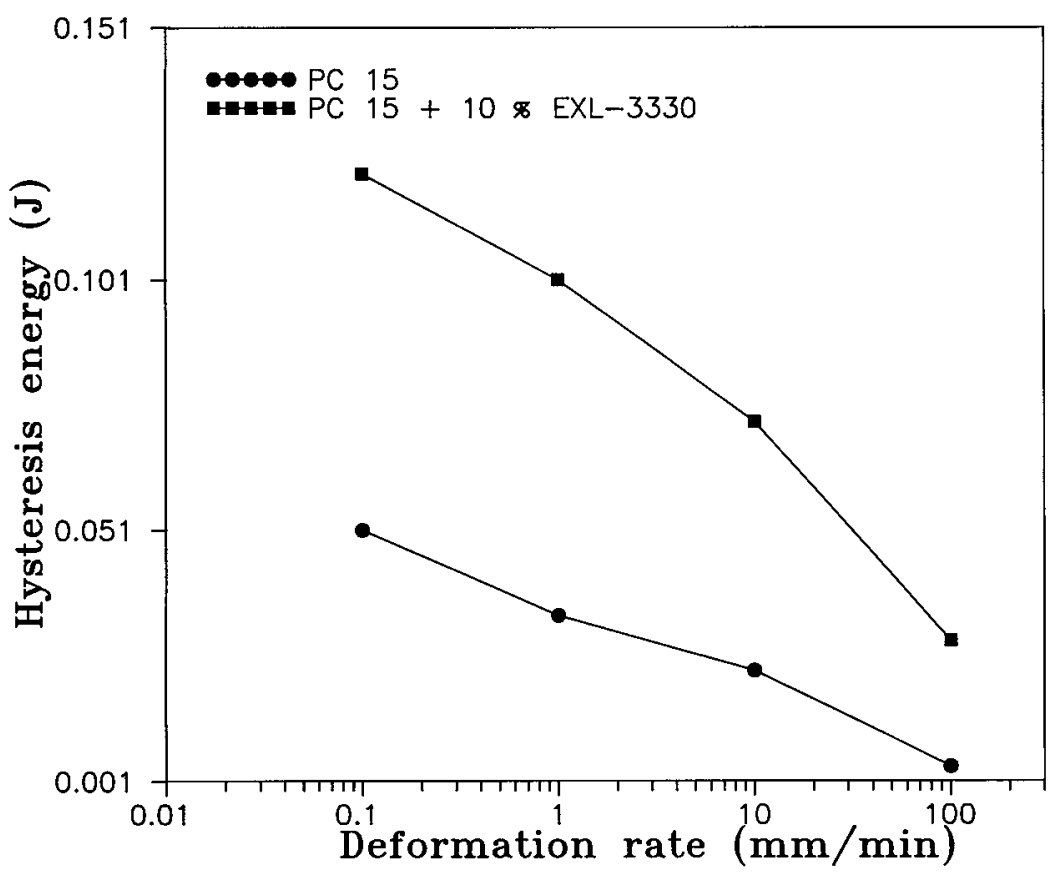

Figure 7 Plots of hysteresis energy versus deformation rate for PC15 and elastomermodified PC15 at a load of $0.15 \mathrm{kN}$.

by a plane-stress mass shear yielding involves a plastic volume much larger than fracture by a plane-strain localized shear yielding. In a toughening mechanism, the presence of elastomer tends to enhance not only the mass shear yielding but also enhances the localized shear yielding. The existence of elastomer can effectively resist earlier crack initiation by inducing a greater extent

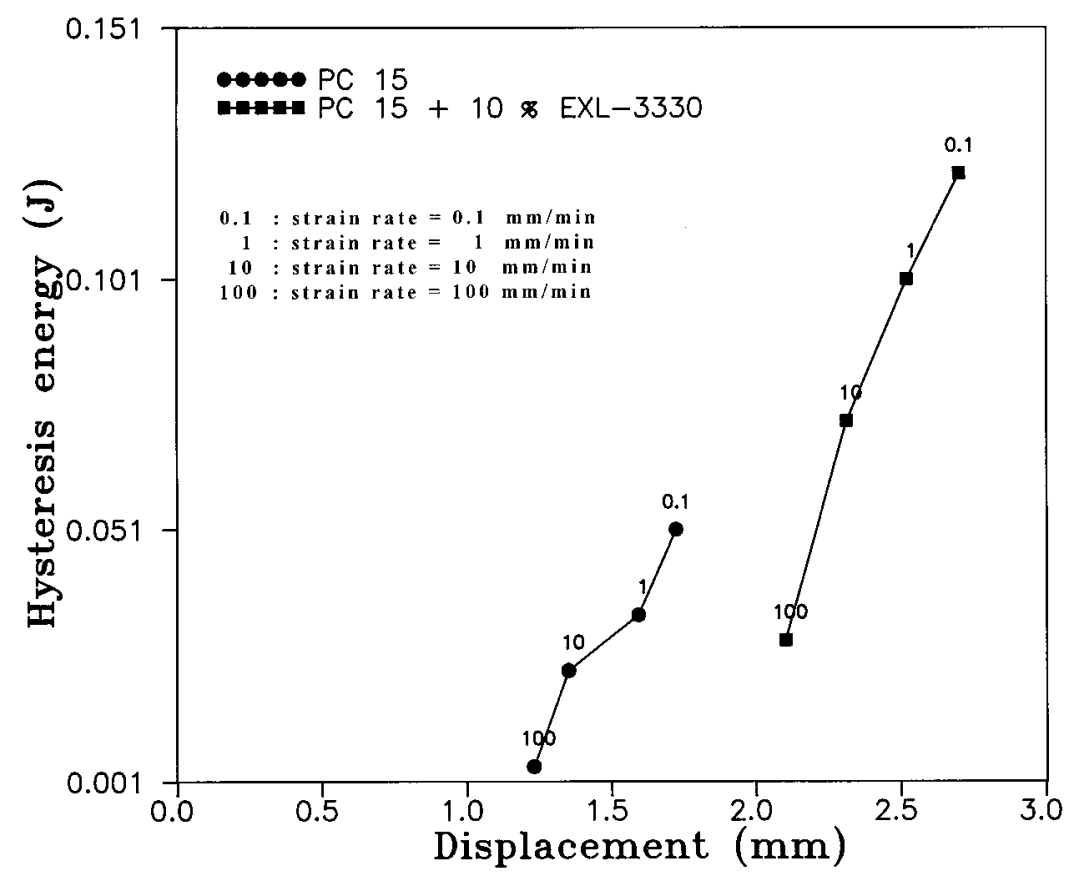

Figure 8 Plots of hysteresis energy versus peak displacement of PC15 and elastomermodified PC15 under different deformation rates. 


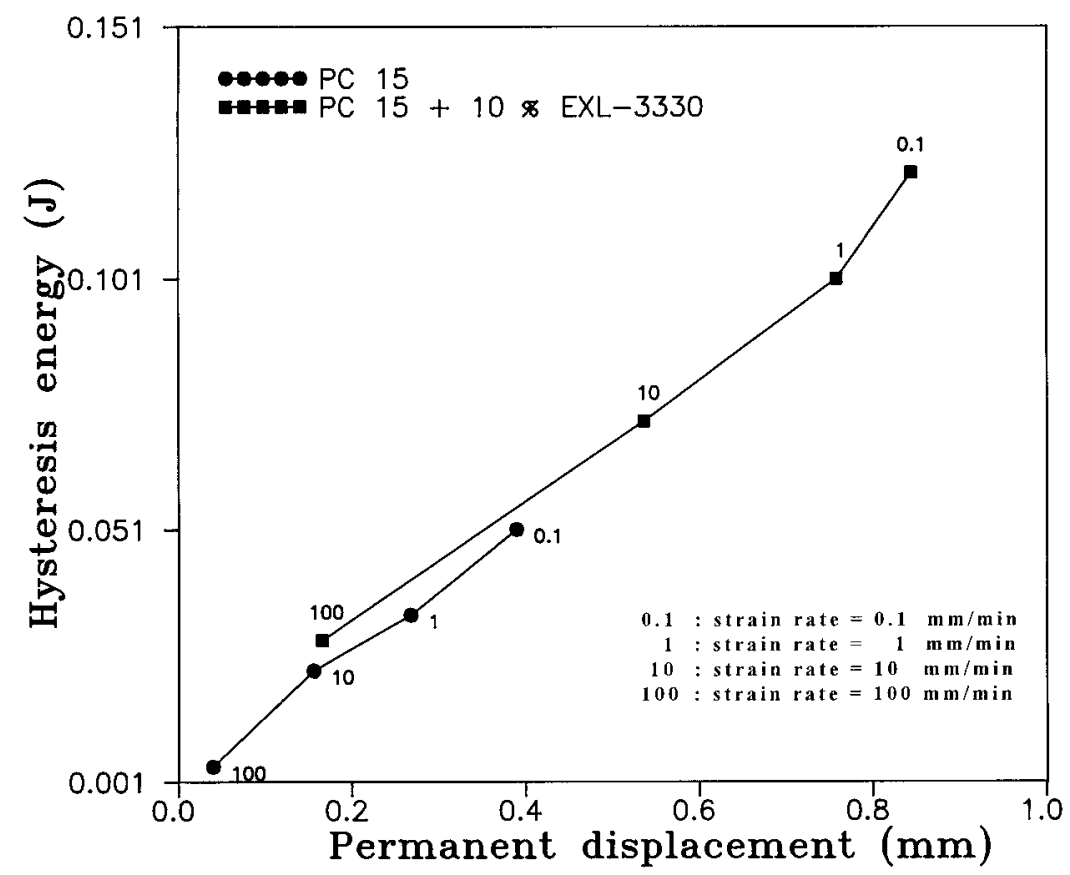

Figure 9 Plots of hysteresis energy versus permanent displacement for PC15 and elastomer-modified PC15 under different deformation rates.

of precrack plasticity (greater hysteresis energy) and results in mass shear yielding ductile fracture and also promotes localized energy dissipations during later crack propagation. The most important factor in determining the DBT behavior is the critical strain energy (in terms of storage energy) for crack initiation, and any effort to improve the ductility of pseudoductile matrices is to delay or retard crack initiation by diverting portions of the input energy into hysteresis plasticity, and allows for the growth of the precrack plastic zone exceeding its critical value..$^{6,12-15} \mathrm{We}$ can also explain the effect of the above results in terms of critical strain rate similar to the concept of critical plastic zone we previously proposed..$^{19}$ We have demonstrated in this study that strain rate is closely related to its precrack plastic zone size (based on hysteresis energy) under identical specimen geometry. We can define a critical strain rate $\left(\dot{\gamma}_{c}\right)$ as the rate required to produce a critical precrack plastic zone to initiate a ductile-mode fracture. If

$$
\begin{aligned}
& \dot{\gamma}_{i}<\dot{\gamma}_{c} \text { and } V_{p}>V_{c} \text { ductile tearing } \\
& \dot{\gamma}_{i} \cong \dot{\gamma}_{c} \text { and } V_{p} \cong V_{c} \quad \begin{array}{c}
\text { brittle/ductile transition } \\
\text { or semiductile }
\end{array} \\
& \dot{\gamma}_{i}>\dot{\gamma}_{c} \text { and } V_{p}<V_{c} \text { brittle failure }
\end{aligned}
$$

$V_{p}$ is the precrack plastic volume at strain rate of $\dot{\gamma}_{i}$ and $V_{c}$ is the critical precrack plastic volume at the critical strain rate of $\dot{\gamma}_{c}$. Quantitatively, $V_{c}$ is a characteristic property of the material if the specimen geometry is fixed. When the applied strain rate $\left(\dot{\gamma}_{i}\right)$ is lower than the critical strain rate $\left(\dot{\gamma}_{c}\right)$, the material is able to divert a greater fraction of the input energy into a greater precrack plastic zone, exceeding the critical volume $\left(V_{c}\right)$ required for a ductile tearing. If the strain rate is greater than the critical strain rate $\left(\dot{\gamma}_{c}\right)$, the material consumes less input energy into hysteresis energy by forming a smaller plastic zone and the crack propagating front can easily pass through the smaller plastic zone, resulting in a brittle failure. Therefore, the DBTR can also be interpreted as the strain rate producing the critical precrack plastic zone where either a ductile mode or a brittle mode failure can take place. From this concept, we can explain the result of Figure 1 as to why the material is at the coexistence of ductile tearing and brittle failure at the deformation rate between 0.1 and $450 \mathrm{~mm} / \mathrm{min}$.

The above descriptions concentrate on initiation only, and are indeed oversimplified for a complicated phenomenon of DBT that should also take into account the complex propagating process in terms of shapes of the crack growth front and the size of the plastic zone. However, the concept of this 
proposed model based on a precrack plastic zone can provide a qualitative but simple way to illustrate any fracture phenomenon.

\section{CONCLUSIONS}

This article continues our studies on the relationship between precrack hysteresis and its ductility of PC in terms of DBT behavior. These results, mainly based on a deformation rate variable, provide further support of the concept of a critical precrack plastic zone mechanism previously proposed in determining the DBT. The precrack elastic storage energy is the major driving force to strain the crack tip for crack initiation. Fracture energy and the precrack hysteresis energy decrease with the increase of deformation rate and with the decrease of $\mathrm{PC}$ molar mass, notch radius, and rubber content. When the deformation rate is lower than the critical deformation rate, the specimen has less storage energy available to strain the crack tip for crack initiation and grows a greater precrack plastic zone. Above the critical plastic zone, the crack growth front will propagate within the plastic zone and results in a ductile fracture. If the deformation rate is nearly equal to the critical rate, either a ductile or a brittle failure will occur. In other words, the DBTR is increased with increasing molar mass and notch radius. Elastomer-induced precrack energy dissipations enhance precrack plasticity and reduce the storage energy to strain the crack tip for crack initiation. The presence of the elastomer will also relieve triaxial stress to delay or retard the onset of the crack initiation, and therefore allows the precrack plastic zone to grow, exceeding the critical value prior to onset of crack initiation. As soon as the precrack plastic zone is greater than the critical value, the crack developed thereafter will propagate within the precrack plastic zone, and result in a ductile fracture.

The authors are grateful to the National Science Council of the Republic of China for the financial support for this research project.

\section{REFERENCES}

1. S. Wu, Polym. Eng. Sci., 30, 72 (1990).

2. S. Wu, Polym. Internat., 29, 229 (1992).

3. S. P. Lyu, X. G. Zhu, and Z. N. Qi, J. Polym. Res., 2, 217 (1995).

4. I. M. Ward, Mechanical Properties of Solid Polymers, 2nd ed., Wiley, Chichester, UK, 1983, pp. 432-436.

5. F. C. Chang, J. S. Wu, and L. H. Chu, J. Appl. Polym. Sci., 44, 491 (1992).

6. F. C. Chang and H. C. Hsu, J. Appl. Polym. Sci., 43, 1025 (1991).

7. F. C. Chang and H. C. Hsu, J. Appl. Polym. Sci., 47, 2195 (1993).

8. F. C. Chang and H. C. Hsu, J. Appl. Polym. Sci., 52, 1891 (1994).

9. C. Bauwens-Crowet, J. C. Bauwens, and G. Homes, J. Polym. Sci., A2, 7, 735 (1969).

10. H. Eyring, J. Chem. Phys., 4, 283 (1936).

11. T. Ree and H. Eyring, in Rheology, Vol. 2, F. R. Eirich, Ed., Academic Press, New York, 1958, p. 83.

12. F. C. Chang, in Handbook of Advanced Materials Testing, Marcel Dekker, New York, 1994, p. 539.

13. W. B. Liu and F. C. Chang, J. Appl. Polym. Sci., 56, 545 (1995).

14. F. C. Chang and H. C. Hsu, Proc. ACS Div. Polym. Mater.: Sci. Eng., 1990, p. 62.

15. F. C. Chang and M. Y. Yang, Polym. Eng. Sci., 30, 543 (1990). 